\title{
Genetic and environmental correlates of morphological variation in a marine fish: the case of Baltic Sea herring (Clupea harengus)
}

\author{
Hanne B.H. Jørgensen, Cino Pertoldi, Michael M. Hansen, Daniel E. Ruzzante, \\ and Volker Loeschcke
}

\begin{abstract}
Baltic Sea herring (Clupea harengus) have been shown to exhibit morphological differences across the marked salinity and temperature gradients in the region. Here we analyse genetic (nine microsatellite loci), morphometric (skull shape), and meristic (pectoral fin rays and number of vertebrae) variations across seven samples of spawning herring collected from four spawning locations in the Baltic Sea to examine whether morphological variation correlates with genetic and (or) environmental factors. Results suggest that herring is adapting to its environment through a combination of selection and plastic responses. Skull shape, including and excluding size variation, differed significantly among samples, both temporally and spatially. Genetic and morphometric distances were correlated, especially when size variation was excluded from the analysis. When size variation was included, skull shape variation was more closely correlated with environmental distances among spawning locations. Vertebrate number differed among samples and was correlated with environmental distances, whereas the number of fin rays was not. Genetic and geographic distances among samples were not correlated.
\end{abstract}

Résumé : On a montré que les harengs (Clupea harengus) de la Baltique présentent des différences morphologiques le long des forts gradients de salinité et de température de la région. Nous analysons la variation génétique (neuf locus microsatellites), morphologique (forme du crâne) et méristique (rayons de la nageoire pectorale et nombre de vertèbres) dans sept échantillons de harengs en fraye récoltés sur quatre sites de reproduction dans la Baltique, afin de déterminer si la variation morphologique est en corrélation avec les facteurs génétiques et (ou) environnementaux. Nos résultats laissent voir que le hareng s'adapte à son environnement par une combinaison de réponses reliées à la sélection et à la structure. La forme du crâne (avec et sans la variation de taille) diffère significativement d'un échantillon à l'autre, aussi bien dans le temps que dans l'espace. Les distances génétiques et morphométriques sont en corrélation l'une avec l'autre, particulièrement lorsque la variation de taille est exclue de l'analyse. Lorsque la variation de taille est incluse, la variation de la forme du crâne devient plus fortement corrélée aux distances environnementales entre les sites de fraye. Le nombre de vertèbres varie d'un échantillon à l'autre et est en corrélation avec les distances environnementales, alors que le nombre de rayons de la nageoire ne l'est pas. Il n’y a pas de corrélation entre les distances génétiques et géographiques au sein des échantillons.

[Traduit par la Rédaction]

\section{Introduction}

When a species' range covers a heterogeneous environment, a single phenotype is unlikely to be associated with high fitness throughout the range (Via et al. 1995). To succeed, a species must be able to match phenotypes with local environments. Historically, local marine fish populations (stocks) have been identified largely using phenotypic traits.
One difficulty when applying such methods is that phenotypic traits are influenced by both genetic and environmental variation and the relative importance of these two sources of variation is generally unknown (Swain and Foote 1999).

In the marine environment, the traditional view of nonexisting or biologically nonsignificant genetic differentiation at regional scales has been challenged by a number of recent studies. Biologically significant (albeit low) population ge-

Received 8 January 2007. Accepted 24 August 2007. Published on the NRC Research Press Web site at cjfas.nrc.ca on 8 February 2008.

J19747

H.B.H. Jørgensen ${ }^{\mathbf{1}, \mathbf{2}}$ and M. Møller Hansen. Danish Technical University, Danish Institute for Fisheries Research, Department of Inlands Fisheries, Vejlsøvej 39, DK-8600 Silkeborg, Denmark.

C. Pertoldi ${ }^{3}$ and V. Loeschcke. Department of Ecology and Genetics, University of Aarhus, Ny Munkegade, Buildg. 540, DK8000 Aarhus C, Denmark.

D.E. Ruzzante. Department of Biology, Dalhousie University, Halifax, NS B3H 1C8, Canada.

${ }^{1}$ Corresponding author (e-mail: hanne.h.jorgensen@agrsci.dk).

${ }^{2}$ Present address: Faculty of Genetics and Biotechnology, University of Aarhus, Blichersallé 20, P.O. Box 50, DK-8830 Tjele, Denmark.

${ }^{3}$ Mammal Research Institute, Polish Academy of Sciences, Waszkiewicza 1c, 17-230 Bialowieza, Poland. 
netic differentiation has been found in highly vagile marine fish (e.g., Atlantic cod (Gadus morhua; Ruzzante et al. 1998; Knutsen et al. 2003) and Atlantic herring (Clupea harengus; McPherson et al. 2001a; Bekkevold et al. 2005; Jørgensen et al. 2005)). The majority of these studies was based on neutral molecular loci (mostly microsatellites) and did not examine evidence of structure at the phenotypic level, though Jørgensen et al. (2005) and Bekkevold et al. (2005) have presented evidence of correlation between genetic structure and variation in environmental factors.

Morphological and ecological variability has been shown to reflect adaptive divergence by natural selection in sympatric populations and species of freshwater and anadromous fish, but marine examples are less common (reviewed by Guinand et al. (2004) and Conover et al. (2006)). Morphological population divergence has been found in studies of pelagic marine fishes such as herring (Ryman et al. 1984) and redfish (Sebastes spp.; Valentin et al. 2002). Populations inhabiting different environments have been shown to exhibit cogradient morphological divergence (e.g., gene expression in the killifish Fundulus heteroclitus (Schulte 2001), accumulation rate of somatic energy stores in Atlantic silverside (Menidia menidia; Schultz and Conover 1997)) and countergradient morphological divergence (e.g., body shape in juvenile cod (Marcil et al. 2006), growth rate in striped bass (Morone saxatilis; Conover et al. 1997)).

Morphological divergence between spawning groups may be due to differences in local environments only, or it could partly reflect genetic differentiation among the spawning groups in cases where there is pronounced homing to spawning locations and low mixing between spawning groups. To identify the most likely scenario in a natural environment, one may combine data on environmental, morphological, and neutral genetic divergence among spawning groups.

The Baltic Sea is one of the world's largest brackish water bodies and constitutes a complex ecosystem with several heterogeneous subunits, each based in a deep basin partially separated from other basins by sills. Surface water temperature decreases gradually from the southeast to the northwest, and inflows of saline water from the North Sea and freshwater from large rivers create a strong salinity gradient (Ojaveer and Elken 1997), which generates a generally unstable and heterogeneous environment.

Biologically significant genetic differences have been reported for Atlantic herring in the transition zone between the highly saline North Sea and the brackish Baltic Sea (Bekkevold et al. 2005; Ruzzante et al. 2006), an area that is generally described as a hybrid zone for a number of marine species (Nielsen et al. 2003, 2004). Within the Baltic Sea itself, herring spawning grounds are found throughout the region (Aro 1989), and geographically separated spawning groups are known to exhibit morphological differences (e.g., Popiel 1984; Parmanne 1990) that have been used for population identification. More recently, genetic studies based on microsatellite markers have identified low but statistically significant differences among herring from some of these areas (Jørgensen et al. 2005), yet it is not well known to what extent morphological and genetic differences correlate with each other.

In this study, we tested the hypothesis that morphological divergence among herring in the Baltic Sea is due to adapta- tion to local environmental conditions by natural selection, at least in part. Salinity and temperature vary throughout the Baltic Sea, and embryos and early larval stages of herring from different spawning and nursery grounds are exposed to different salinity and temperature regimes (e.g., Klinkhardt 1996). Herring larvae from different areas of the Baltic Sea are thus likely to exhibit different tolerance levels to these two environmental parameters. Further, as the species composition of mesozooplankton communities is dependent on salinity and temperature (Möllmann et al. 2000), different prey items are available for young herring in the different areas of the Baltic Sea (Möllmann et al. 2004).

To test for correlation between genetic and morphological differentiation, as well as their correlations with environmental variability among spawning groups, we estimated (i) neutral molecular genetic differentiation using nine microsatellite loci, (ii) meristic differentiation among those same groups using the number of pectoral fin rays and the number of vertebrae, two meristic traits previously shown to vary geographically in herring, (iii) morphometric differentiation using a geometric morphometrics approach in which we tested for differences in morphological differentiation among samples and age groups using the relative position of homologous landmarks placed on herring skulls, and (iv) correlations of neutral genetic and morphological differentiation with geographic and environmental distances among spawning groups. Our study design did not allow for directly testing for genetically based local adaptation, but we tested for indications of local adaptation by natural selection using an indirect approach. The tests are expected to indicate which factors might influence morphological variation in herring in the Baltic Sea.

\section{Materials and methods}

\section{Samples}

Atlantic herring were collected from four spawning locations in the Baltic Sea: ( $i$ ) near the island of Rügen (RU; two collections, March 2003 and May 2003), (ii) in the Gulf of Riga (RI; one collection, 2003), (iii) in the Åland Archipelago (AL; two collections, 2002 and 2003), and (iv) off the Swedish coast of the Bothnian Bay (BB; two collections, 2002 and 2003) (Fig. 1; Table 1). The sampling design was based on previously recognized spawning groups (Ojaveer and Elken 1997) located in different areas of the Baltic Sea that were defined based on zones of increased genetic and environmental differentiation (Jørgensen et al. 2005). Herring in six of the seven samples were in prespawning or spawning condition (maturity stage five or six; Anonymous 1962), the exception being the sample from AL in 2003 (AL03) in which the majority of the specimens were in postspawning condition. Regardless of maturity stage, they were all caught on their respective spawning grounds. The samples were frozen upon arrival at the Danish Institute for Fisheries Research and stored at $-18{ }^{\circ} \mathrm{C}$. A piece of gill tissue was removed from each specimen and stored in $96 \%$ ethanol for subsequent DNA extraction.

\section{Genetic analyses}

DNA was extracted from gill tissue using the Chelexproteinase K protocol by Estoup et al. (1996), the hot so- 
Table 1. Catch data for the Atlantic herring (Clupea harengus) samples included in the present study.

\begin{tabular}{lllll}
\hline & & & \multicolumn{2}{c}{ Sample size } \\
\cline { 4 - 5 } Sample (code) & Sampling location & Sampling date & $n^{a}$ & $n^{b}$ \\
\hline Bothnian Bay (BB02) & $63.38^{\circ} \mathrm{N}, 20.25^{\circ} \mathrm{E}$ & June 2002 & 94 & 116 \\
Bothnian Bay (BB03) & $63.38^{\circ} \mathrm{N}, 20.15^{\circ} \mathrm{E}$ & June 2003 & 59 & 115 \\
Åland Archipelago (AL02) & $60.20^{\circ} \mathrm{N}, 22.10^{\circ} \mathrm{E}$ & June 2002 & 55 & 115 \\
Åland Archipelago (AL03) & $60.20^{\circ} \mathrm{N}, 22.10^{\circ} \mathrm{E}$ & June 2003 & 88 & 109 \\
Gulf of Riga (RI03) & $\mathrm{ICES} 44 \mathrm{H} 2^{\mathrm{R}}$ & May 2003 & 80 & 109 \\
Rügen (RU0303) & $54.14^{\circ} \mathrm{N}, 13.27^{\circ} \mathrm{E}$ & March 2003 & 54 & 100 \\
Rügen (RU0503) & $54.11^{\circ} \mathrm{N}, 13.26^{\circ} \mathrm{E}$ & May 2003 & 81 & 100 \\
\hline
\end{tabular}

Note: All individuals were caught on the spawning grounds and in spawning condition. The position given for the Gulf of Riga sample refers to the ICES (International Council for the Exploration of the

Sea) management area $44 \mathrm{H} 2$ in the northwestern part of the Gulf.

${ }^{a}$ Sample sizes in morphometric analyses.

${ }^{b}$ Sample sizes in genetic analyses.

Fig. 1. Sampling locations: RU, Greifswalder Bodden near the German island of Rügen; RI, the Gulf of Riga; AL, the Alland Archipelago; BB, the Southern Bothnian Bay at the Swedish coast. The exact position for each sample is shown in Table 1.

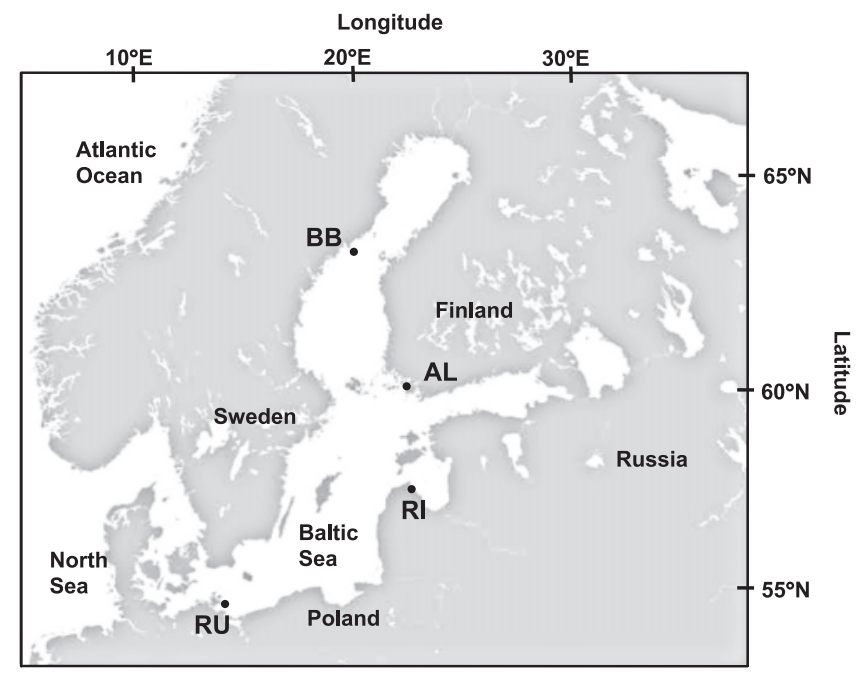

dium hydroxide and Tris (HotSHOT) protocol by Truett et al. (2000), or the DNeasy ${ }^{\circledR}$ Tissue Kit 250 (Qiagen Sample and Assay Technology, Hilden, Germany). Nine microsatellite markers were analyzed: CHA1017, CHA1020, CHA1027, CHA1202 (McPherson et al. 2001b), CPA101, CPA107, CPA111, CPA112, and CPA114 (Olsen et al. 2002). The microsatellite loci were polymerase chain reaction (PCR) amplified using standard reagents, and their annealing temperatures ranged from $54-60{ }^{\circ} \mathrm{C}$ for the different loci (exact protocols are available from the first author on request). The PCR products were analyzed on the BaseStation $51^{\mathrm{TM}}$ DNA fragment analyzer (MJ Research, Inc., Waltham, Massachusetts), and gels were typed using the software Cartographer (version 1.2.6; MJ Geneworks, Inc., San Francisco, California). As a quality control measure to minimize the probability of genotyping errors (Bonin et al. 2004), we (i) included two standard individuals in each gel to improve typing consistency, (ii) re-analyzed between $10 \%$ and $20 \%$ of the individuals from each sample, depending on the marker, to minimize the risk of misinterpretation of gels, and (iii) applied the software Micro-Checker (version 2.2.0; van Oosterhout et al. 2003) to test for the presence of null alleles, stuttering, and large allele dropouts.

Tests for conformity to Hardy-Weinberg expectations were conducted using GENEPOP (version 3.3; Raymond and Rousset 1995) according to the procedure by Guo and Thompson (1992). Weir and Cockerham's (1984) $\theta$, an unbiased estimator of $F_{\mathrm{ST}}$, and exact pairwise tests (Goudet et al. 1996) were used to estimate pairwise genetic differentiation between samples using FSTAT (version 2.9.3; Goudet 1995). The $P$ values were compared with Dunn-Šidák significance levels (Sokal and Rohlf 1995) adjusted to $k=21$ (the number of pairwise comparisons). These tests were supported by a hierarchical analysis of molecular variance (AMOVA) as implemented in Arlequin (version 3.11; Excoffier et al. 2005). With the AMOVA, we estimated the proportions of genetic differentiation that could be attributed to differentiation among spawning locations and between temporal samples within spawning locations, the significances of which were tested using 10000 randomizations.

\section{Meristic traits and age determination}

In Atlantic herring, the number of pectoral fin rays and the number of vertebrae are well suited for the identification of separate spawning groups (Parsons 1972), and in the present study, we examined both traits. Age determination was based on the number of winter rings in otoliths following standard procedures (International Council for the Exploration of the Sea 2003). Kruskal-Wallis rank sum tests (Zar 1996) were used to test for differentiation in the medians of pectoral fin rays, vertebrae, and age among locations, and two-sample Wilcoxon rank sum tests were used to test for differentiation between early and late temporal samples using S-PLUS (version 6.1; Insightful Corp. 2002) and JMP (SAS Institute Inc. 1997).

\section{Morphometric analyses}

\section{Digitizing homologous landmarks}

Geometric morphometric methods have been used to compare body shape among species or populations of fish (e.g., Klingenberg et al. 2003; Neves and Monteiro 2003; Langer- 
hans and DeWitt 2004). We chose the skull for these morphometric investigations because of its presumed ability to reflect any local adaptations in feeding biology. The large number of connected, inflexible bony structures in the head are not worn or broken by influences from the external environment. To detach soft tissue from the bony structures, heads were placed in boiling water. Skulls were carefully placed on modeling clay and photographed from above with a Nikon Coolpix 990 digital camera (Nikon Corp., Tokyo, Japan) fastened to a tripod and set at $1280 \times 1024$ pixel resolution. Each picture included a ruler for scaling. We applied the geometric morphometrics (GM) approach (e.g., Bookstein 1996). Advantages of this approach include (i) allowing for statistical analyses of overall shape variation and the generation of graphical illustrations of shape differences (e.g., Caldecutt and Adams 1998; Rüber and Adams 2001) and (ii) capturing all aspects of shape change among a set of landmarks without a priori knowing for which specific anatomical change to search (Adams and Rohlf 2000).

The GM analyses of skull shape were based on 26 digitized homologous landmarks. Any variation in shape due to position, rotation, or scale was removed by a generalized Procrustes analysis (described in Rohlf 1999; Adams et al. 2004). After this, shape was represented as partial warps, which describe the deviation in shape for each landmark between individual herring and the sample mean (Rohlf 1999). Landmark digitization was repeated five times on 10 randomly chosen specimens to estimate variability in digitization using separate analyses of variance (ANOVAs; PAST, version 1.21; Hammer et al. 2004). The variation among individuals was significantly higher than within individuals in 44 of 48 cases. The $\mathrm{MS}_{\text {error }}$ for all partial warps and the uniform component were in the order of $10^{-6}$, and hence, measurement error is not a concern in this study.

\section{Correcting for size effects}

The skull size was estimated as the centroid size (CS), the square root of the sum of squared distances between the digitized landmarks and the centroid in all dimensions (Adams and Funk 1997). To test for overall size differences among the seven samples, we conducted a two-way ANOVA with spawning location and spawning time as independent variables and $\log \left(\mathrm{CS}_{i j}\right)$ as the dependent variable. Pairwise tests to compare centroid size in all pairs of samples ( $t$ tests and Wilcoxon two-sample tests) were conducted using PAST (version1.21; Hammer et al. 2004).

Allometric growth effects could potentially create spurious differences among samples in shape analysis. Therefore, we used two approaches to minimize the impact of allometric growth effects. (i) All 46 partial warps and uniform component scores were adjusted for allometric effects using the following equation (Swain et al. 1991):

$$
A_{i j}=W_{i j}+b_{j}\left[\log (\mathrm{CS})-\log \left(\mathrm{CS}_{i j}\right)\right]
$$

where $W_{i j}$ is the nonadjusted partial warp for individuals $i$ in sample $j, b_{j}$ is the regression slope for warp score vs. $\log (\mathrm{CS})$ within group $j$, CS is the grand mean centroid size (here 60.180), and $\mathrm{CS}_{i j}$ is the centroid size for individual $i$ in sample $j$. (ii) A canonical variates analysis using PAST (version1.21; Hammer et al. 2004) was conducted on the ad- justed data. Of the morphometric variance, $76.07 \%$ was contained along the first axis, 8.28\% was contained along the second axis, and $15.65 \%$ was distributed along the remaining canonical variates axes (CVAs). The correlation between CVA 1 and $\log \left(\mathrm{CS}_{i j}\right)$ was still considerable (Pearson's $r=$ 0.616), indicating that shape variation was not independent from size variation despite the adjustment for allometric effects. Because of this scaling effect on CVA 1, all following tests were conducted both including and excluding CVA 1 to identify any impact on the results from scaling effects.

\section{Testing for variation in shape}

To test for differentiation in shape among samples, we first performed a two-way multivariate analysis of variance (MANOVA) with spawning location and spawning time as independent variables and shape (represented by the seven first CVAs) as the dependent variable to test for differences in shape among samples in S-PLUS (version 6.1; Insightful Corp. 2002). To identify any confounding dissimilarities among age groups within spawning locations, we then conducted one-way MANOVAs (PAST, version1.21; Hammer et al. 2004) for each age group separately with spawning location as the independent variable. Each age group consisted of a cohort (e.g., individuals of age 3 in 2002 and age 4 in 2003 at the same spawning location), forming a total of six age groups. The results of pairwise tests for shape differentiation supported MANOVA results and are not presented.

The loadings along the first two canonical axes were plotted for each specimen to illustrate variation within, versus among, locations (Fig. 2) (multigroup discriminant analysis; Hammer et al. 2004). Finally, the mean landmark configuration for each of the seven samples was compared with the overall consensus, and the resulting deviations were illustrated as deformations of so-called thin-plate splines using the software tpsRegr (version1.28; Rohlf 2003) (Fig. 3b).

\section{Spatial analyses}

To test for correlations between genetic, geographic, and morphometric distances among spawning groups, we performed partial Mantel tests (Legendre and Legendre 1998) using the program IBD (version1.5; Bohonak 2002). Genetic distances were represented by pairwise $\theta$ values. The input matrix for geographic distances contained the shortest waterway distances between sampling locations, estimated using the GIS program ArcMap (version 8.3; ESRI Corporation, Redlands, California). Morphometric distances were represented as the pairwise Mahalanobis' distances among samples. This distance measure describes the similarity between data sets while taking into account the correlation between data in the data sets, and it is not scale-dependent (Manly 1994). Genetic and geographic distances were log-transformed, and each test was based on 10000 randomizations. We then tested for correlation between geographic and morphometric distances using the Mantel test option in Genetix (version 4.04; Belkhir 2000). The input file contained log-transformed geographic distances and pairwise Mahalanobis' distances estimated both including and excluding CVA 1. Similar procedures were used to test for correlations between morphological and environmental distances (differences in monthly mean values of minimum, maximum, and mean salinity and surface water temperature on the spawning and (or) nursery locations; further details on environmental data are given in 
Fig. 2. Canonical variates (CVA) plots including scaling effects in the left column and excluding scaling effects in the right column: (a) age group $1(3+4$ years); $(b)$ age group $2(4+5$ years); $(c)$ age group $3(5+6$ years); $(d)$ age group $4(6+7$ years); and $(e)$ age group $5(7+$ 8 years). Southern Bothnian Bay at the Swedish coast (BB), $\times$; the Alland Archipelago (AL), $\bigcirc$; the Gulf of Riga (RI), $\triangle$; Greifswalder Bodden near the German island of Rügen (RU), $\square$. Ellipses represent $95 \%$ confidence areas. Note different scaling on the $y$ axes.

(a)

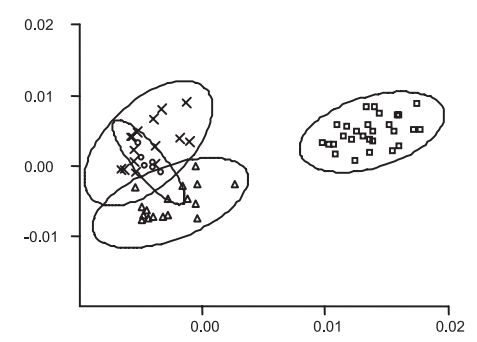

(b)

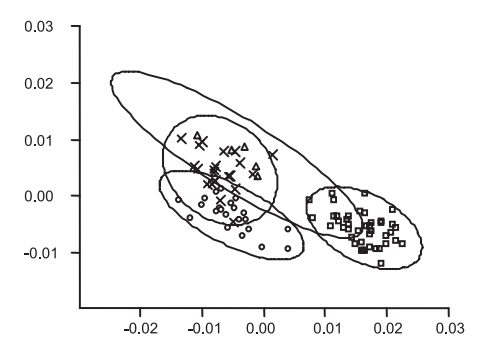

(c)

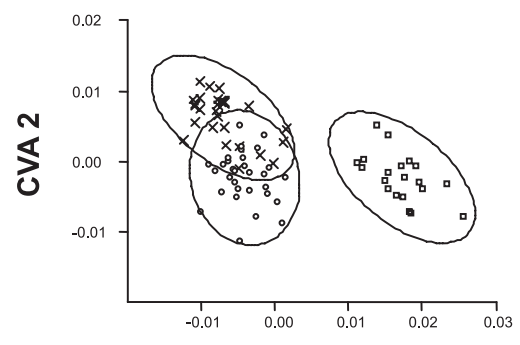

(d)

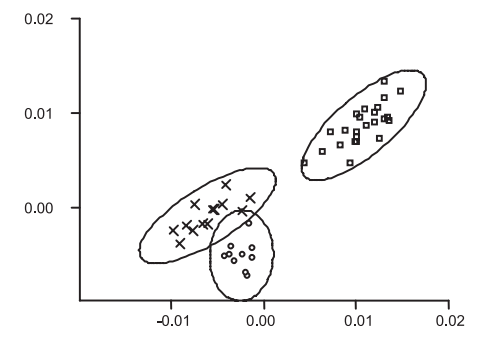

(e)

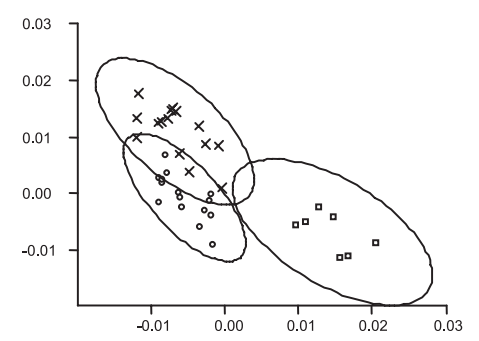

- scaling
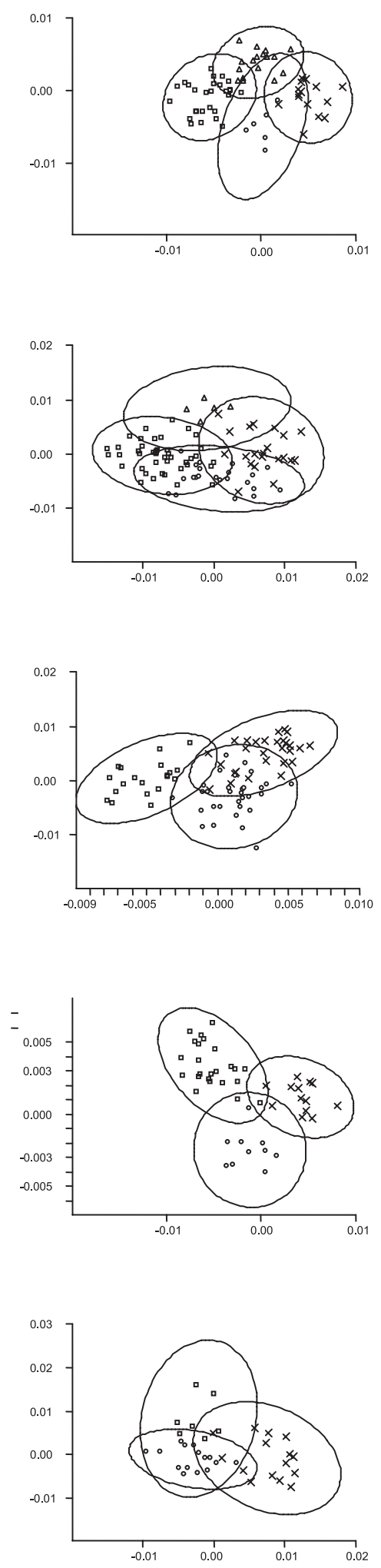
Fig. 3. (a) The homologous landmarks digitized on each specimen. There were 26 landmarks in total, but only one of each pair of bilateral landmarks is indicated by arrows in the photo. (b) Thin-plate spline representations of the variation in shape along CVA 1 and CVA 2 after adjusting partial warps and uniform components for size according to Swain et al. (1991). The deformations are shown in a $3 \times$ magnification.

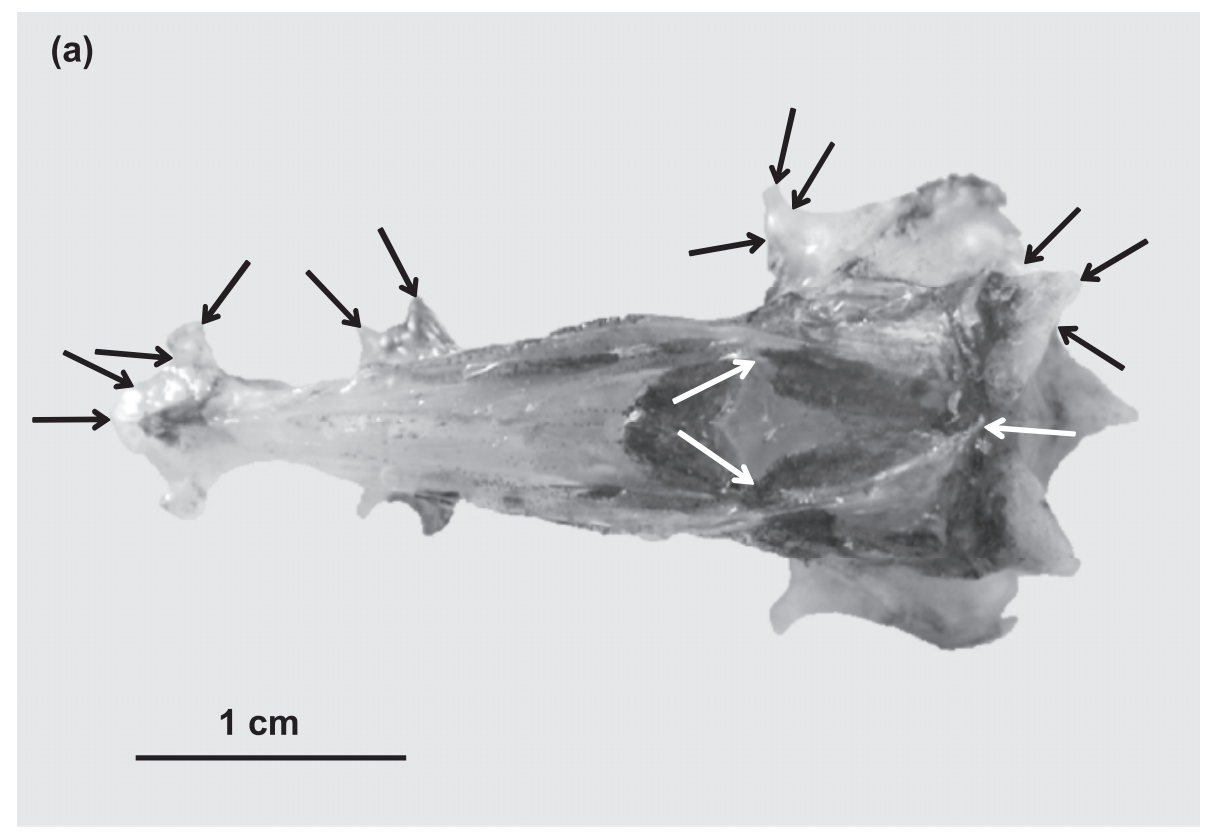

(b)

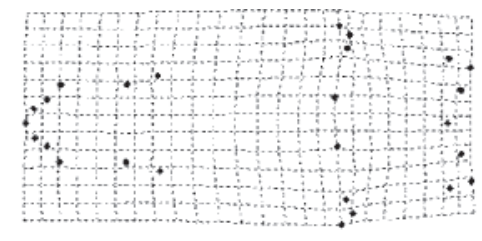

CVA 1
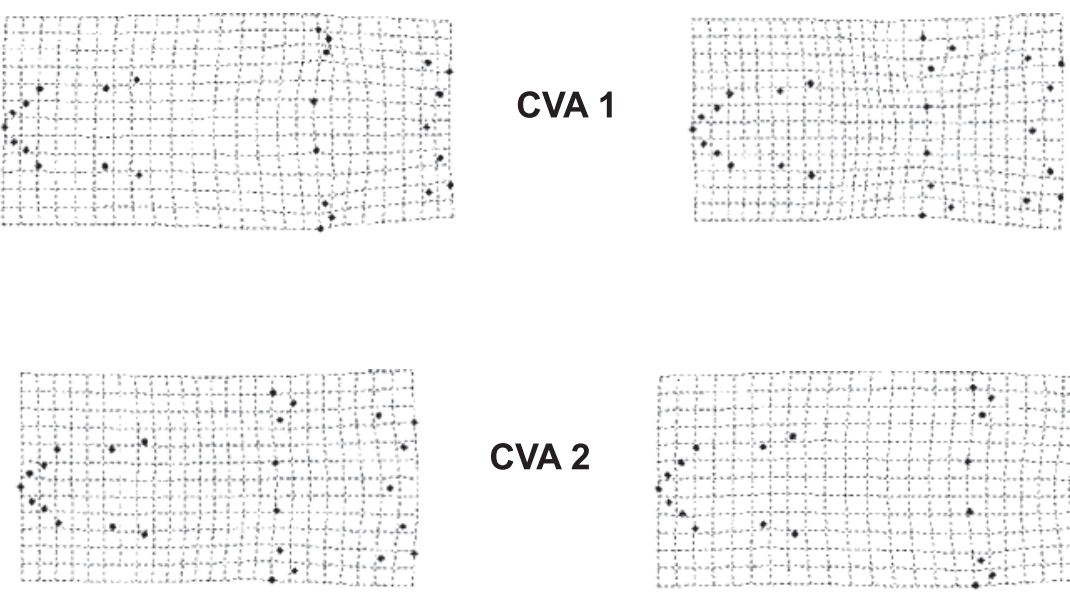

CVA 2

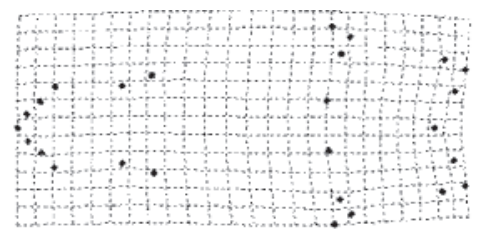

Jørgensen et al. (2005)). Each Mantel test was based on 10000 permutations.

\section{Results}

\section{Genetic analyses}

Of the 63 tests for departure from Hardy-Weinberg expectations, only two $(3.2 \%$, i.e., fewer than the $5 \%$ expected by chance alone) yielded a significant outcome (Appendix A). Before the multiple-test Dunn-Šidák adjustment of the $\alpha$ level, the RU samples differed from all other samples, and the temporal samples from the Aland Archipelago (AL02 and AL03) differed from each other. These differences disappeared after adjustment for multiple tests (Table 2). The hierarchical AMOVA supported the pairwise tests. The vari-

ance among spawning locations did not contribute significantly to the overall genetic variance $\left(F_{\mathrm{CT}}=0.005, p=\right.$ 0.11 ), whereas the variance between temporal samples within spawning locations did contribute significantly $\left(F_{\mathrm{SC}}=0.001, p=0.03\right)$.

\section{Meristic and age analyses}

The mean number of pectoral fin rays ranged from 17.33 (AL02) to 17.85 (RU0303). The mean number of vertebrae ranged from 54.86 (AL03) to 55.98 (RU0503). Overall, this led to a significant difference in the number of vertebrae among spawning locations $(P<0.001)$ and between temporal samples within location at Rügen (RU, $P=0.005$, mean number of vertebrae 55.98 and 55.62) but not at the other locations for which temporal samples were available (BB, 
Table 2. Pairwise $\theta$ values (Weir and Cockerham 1984) between samples of Atlantic herring (Clupea harengus).

\begin{tabular}{lcclllll}
\hline & BB02 & BB03 & AL02 & AL03 & RI03 & RU0303 & RU0503 \\
\hline BB02 & 0 & & & & & & \\
BB03 & -0.0008 & 0 & & & & & \\
AL02 & 0.0009 & -0.0001 & 0 & & & & \\
AL03 & -0.0004 & 0.0018 & $\mathbf{0 . 0 0 3 3}$ & 0 & & \\
RI03 & 0 & -0.0005 & 0.0013 & 0.0001 & 0 & & \\
RU0303 & $\mathbf{0 . 0 0 9 7}$ & $\mathbf{0 . 0 1 1 3}$ & $\mathbf{0 . 0 1 0 9}$ & $\mathbf{0 . 0 1 0 6}$ & $\mathbf{0 . 0 0 6 8}$ & 0 & \\
RU0503 & $\mathbf{0 . 0 1 2 9}$ & $\mathbf{0 . 0 1 4 7}$ & $\mathbf{0 . 0 1 5 8}$ & $\mathbf{0 . 0 1 4 7}$ & $\mathbf{0 . 0 1 1 1}$ & 0.0012 & 0 \\
\hline
\end{tabular}

Note: None of the exact pairwise tests (Goudet et al. 1996) showed significant differentiation when compared with an $\alpha$ level Dunn-Šidák adjusted to $k=21$. Values in bold type indicate significant differentiation before Dunn-Šidák adjustment of the $\alpha$ level. See Table 1 for explanation of sample codes.

Table 3. One-way multivariate analyses of variance (MANOVAs) testing for shape differences among Atlantic herring (Clupea harengus) spawning locations for each age group separately.

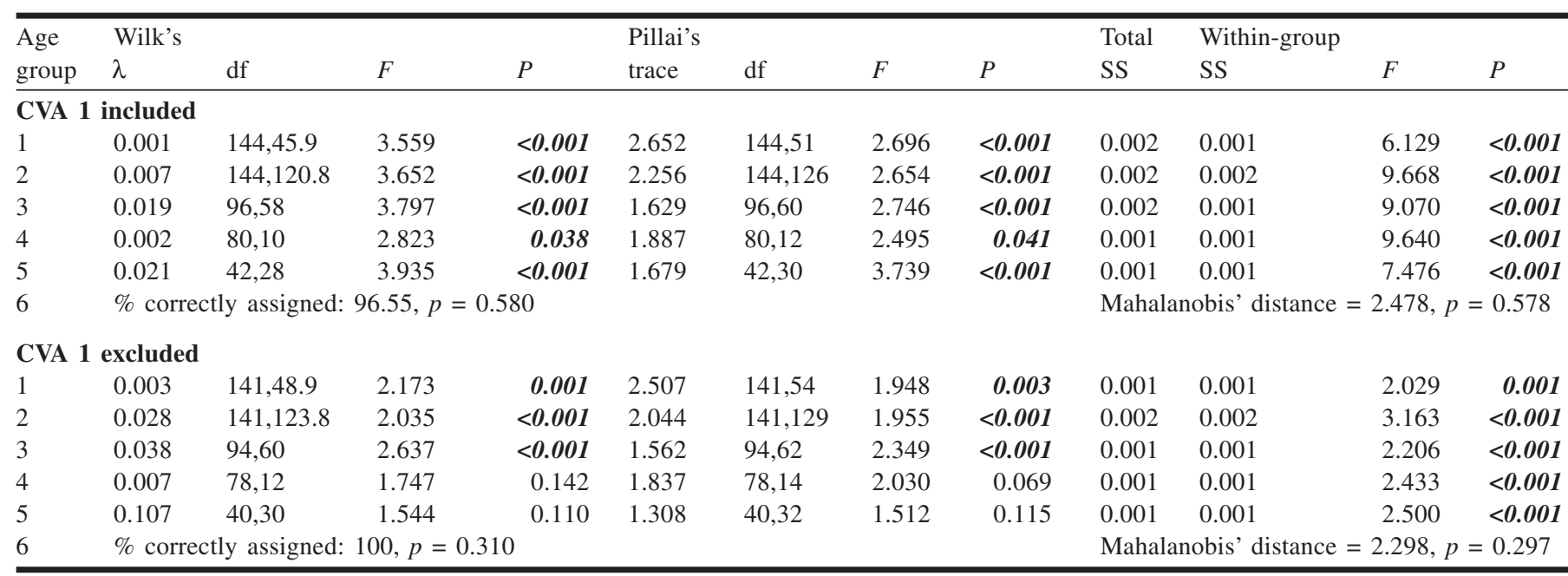

Note: Results from the parametric MANOVA are shown as Wilk's $\lambda$ (with associated df, $F$, and $P$ values) and Pillai's trace (with associated df, $F$, and $P$ values). Results from the nonparametric MANOVA are shown as sum of squares (SS) values and associated $F$ and $P$. Age group 6 was only represented in $\mathrm{AL}$ and $\mathrm{BB}$; therefore, pairwise tests were conducted for this age group. $P$ values in bold italic type indicate significant differences in shape among spawning locations.

$P=0.117$, mean number of vertebrae 55.11 and 55.31 ; AL, $P=0.833$, mean number of vertebrae 55.45 and 54.86$)$. The number of pectoral fin rays showed overall nonsignificant differentiation among spawning locations $(P=0.231)$, whereas differences were significant between temporal samples at $\operatorname{AL}(P=0.032$, mean number of rays 17.33 and 17.65). Age distributions differed significantly among locations $(P<0.001)$ and between temporal samples at AL and RU (BB, $P=0.093$; AL, $P<0.001$; RU, $P<0.001)$. Ages for the samples, expressed as sample (mean age in years, median age in years), were as follows: $\operatorname{SB} 02(5.83,6) ; \mathrm{SB} 03$ (5.18, 5); AL02 (8.04, 8); $\operatorname{AL03~(6.33,~6);~RI03~(3.38,~3);~}$ RU0303 (5.98, 6); and RU0503 (5.17, 5).

\section{Morphometric analyses}

Fish size as represented by $\log \left(\mathrm{CS}_{i j}\right)$ differed significantly among samples, both spatially and temporally ( $P$ (location) $<$ $0.001 ; P($ time $)<0.001 ; P($ location $\times$ time $)=0.622)$. Skull shape also differed among samples, both spatially and temporally ( $P$ (location), $P$ (time), and $P$ (location $\times$ time) were all $<0.0001$ including and excluding CVA 1). Parametric MANOVAs and nonparametric one-way NP-MANOVAs revealed that skull shape (including CVA 1) differed signifi- cantly among the four spawning locations $(0.001<P \geq$ 0.041; Table 3 ) for age groups 1 to 5 (the results are shown in Fig. 2). Landmark configurations are presented as thinplate splines and show that the shape variation is largest in the neurocranial region of the skull, whereas the snout is less variable (Fig. 3b). Along CVA 1, the shape change is mainly an expansion-contraction of the central skull, and the shape change along CVA 2 represents mainly width changes of the posterior part of the skull.

\section{Spatial tests}

Partial Mantel tests showed no significant correlation between genetic distances ( $\theta$; Weir and Cockerham 1984) and geographic distances (Table 4a). Morphometric distances, however, were significantly correlated with genetic distances (Table 4a). If geographic distance was controlled for, morphometric and genetic distances were correlated when size differences were included (i.e., including CVA 1) but not when size differences were removed (i.e., CVA 1 excluded) (Table 4a). Skull shape differences were correlated with geographic distances (Pearson's $r=0.517, P=0.026$ ) when size differences were included (i.e., including CVA 1) but not otherwise (Pearson's $r=-0.367, P=0.782$ ). Morphometric distances 
Table 4. (a) Partial Mantel tests for correlation between geographic, genetic, and morphometric distances among samples of Atlantic herring (Clupea harengus). (b) Mantel tests for correlation between morphometric distances and environmental distances between the spawning and (or) nursery grounds in the month of peak spawning activity with salinity in the upper panel and temperature in the lower panel.

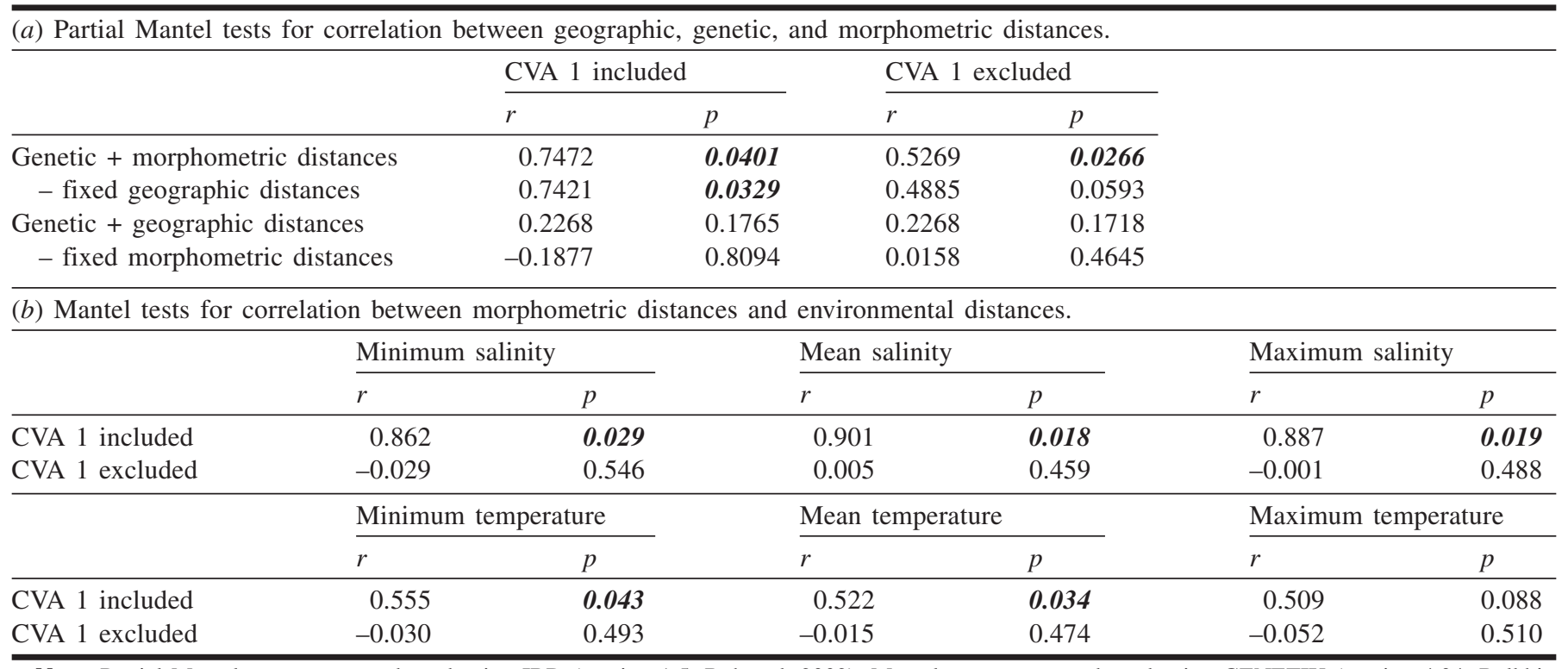

Note: Partial Mantel tests were conducted using IBD (version 1.5; Bohonak 2002); Mantel tests were conducted using GENETIX (version 4.04; Belkhir 2000); $r$ values represent Pearson's $r$ (Manly 1994). $P$ values in bold italic type indicate significant correlations between morphometric distance and environmental distance.

were correlated with environmental distances when size was included but not when size was excluded (Table $4 b$ ).

\section{Discussion}

\section{Spatial population structure}

Using genetic, meristic, and morphometric approaches, we found evidence of spatial and temporal differentiation among samples of spawning Atlantic herring. Genetic and morphometric distances were correlated even when size was controlled for, but they were not correlated with environmental distances. Conversely, shape differentiation including size variation and mean vertebrate counts was correlated with environmental distances. Below we discuss these findings and their implications in detail.

\section{Molecular genetic population structure}

Genetic differentiation was generally low, as is typically the case in marine fishes (DeWoody and Avise 2000). The question is whether the differentiation is significant or not. Tests for pairwise differentiation usually involve a relatively high number of repeated tests, resulting in a conservative $\alpha$ level when table-wide significance levels are applied. Therefore, we found no significant pairwise genetic differentiation overall. An AMOVA also showed nonsignificant genetic variation among spawning location, but this is in contrast to a previous AMOVA that included more samples (Jørgensen et al. 2005). In addition, the $\theta$ values from tests involving Rügen (RU) samples showed significant genetic differentiation when tests were considered separately. The four spawning locations included in the present study were found to belong to three areas characterized by relatively high genetic differentiation among areas and very low differentiation within areas (Jørgensen et al. 2005). Our RU samples are separated from the remaining Baltic Sea herring. Gulf of Riga (RI) herring belong to a Baltic Proper associated area, whereas the Åland Archipelago (AL) and Bothnian Bay (BB) samples belong to groups of herring feeding and spawning in basins to the northeast of the Baltic Proper.

No isolation by distance was found among spawning locations, which, in part, may be due to the genetic differentiation between temporal samples (which have a zero geographic distance). Though low, temporal genetic differentiation was significant according to the AMOVA.

\section{Population structure of meristic traits}

Although the number of vertebrae differed significantly among the four spawning locations in this study, the number of pectoral fin rays did not. There was a significant correlation between differences in salinity between localities and differences in vertebrate numbers, indicating that the variation among spawning groups may be due to different salinities on the spawning and (or) nursery grounds. No such correlation was found for the number of fin rays.

\section{Morphometric population structure}

Genetic and morphometric distances were correlated even after controlling for geographic distances. The skull bones were expected to reflect differences in feeding among populations. Morphometric analysis of the skulls shows that herring from different spawning locations differ in skull shape, and these results are consistent with the molecular data. Both types of data indicate that RU samples show relatively large differentiation (high $\theta$ values and large Mahalanobis' distances) from other samples, implying that herring from this location were distinct from herring from other locations. 
This is consistent with the fact that RU herring feed in the Danish waters where salinity is much higher than in the basins of the Baltic Sea that constitute feeding areas of the remaining herring included here (Aro 1989).

Morphometric distances were significantly correlated with geographic distances when size variation (CVA 1) was included, but nonsignificant when size variation (CVA 1) was excluded. Size was probably correlated to geographic distance mainly because the Rügen (RU) samples have by far the largest distances to the remaining samples, both when size and geographic distance are considered.

The number of samples is relatively low, and consequently the results of Mantel tests should be treated with caution. Nevertheless, two results - (i) the lack of morphometric isolation by distance when excluding size variation (CVA 1) and (ii) significant correlation between genetic and morphometric distances - may indicate that skull shape without the influence of size variation is more closely associated with neutral genetic variation (assuming that microsatellites are neutral).

\section{Temporal population structure}

At $\mathrm{BB}$ and $\mathrm{RU}$ we found no basis for rejecting the null hypothesis of temporal genetic stability, but the Aland (AL) 2002 and 2003 samples differed genetically before DunnŠidák correction. Nevertheless, despite the absence of temporal genetic differences at localities BB and RU, we found significant differentiation in multivariate shape between temporal samples within locations, even when the scaling effect was removed. Furthermore, the number of vertebrae and the number of pectoral fin rays differed significantly between temporal samples at RU and AL, respectively.

We tested for confounding effects due to temporal population structure at three locations, BB, AL, and RU. The samples from $\mathrm{BB}$ and $\mathrm{AL}$ were taken 1 year apart, whereas the samples from RU were taken at the beginning and the end of the springspawning season of 2003. It is likely that the temporal morphological differentiation is caused by different environmental conditions at the time of hatching and early growth as temporal genetic differentiation was only found at AL.

Because mean age differed significantly among samples, shape was compared independently for different age groups. There were differences in shape among spawning locations within all age groups for which we had representative samples from all locations.

\section{Factors shaping population structure}

We compared several distance measures by correlation analyses and found that genetic and morphometric distances were correlated, especially when size variation was excluded from the analysis. When size variation was included, skull shape variation was more closely correlated with environmental distances among spawning locations. This suggests that shape may be more strictly genetically controlled, whereas size shows plastic responses to environmental factors. Similar conclusions were reached in studies on morphological structures as different as the skull shape of Iberian lynx (Lynx pardinus; Pertoldi et al. 2005), molar teeth in lab mice (Workman et al. 2002), and wing venation in fruit fly (Drosophila melanogaster; Birdsall et al. 2000). Genetic and geographic distances among herring samples were not correlated, making an isolation by distance population structure unlikely.
By means of the canonical variates analysis of the partial warps adjusted for allometric effects, we placed all shape variation due to scaling effects along the first canonical axis. Approximately $76 \%$ of the total shape variance was explained by this axis. It should be noted that body size variation is not just a "noise component", but an important variable that needs to be considered in shape analyses (Swain and Foote (1999) and references therein). Therefore, all analyses in this study were conducted with and without CVA 1. From this, we can conclude that most of the shape variation among spawning locations is due to the significant size-induced differences, but the remaining $24 \%$ of the shape variation still explains a significant proportion of the differentiation. Conversely, a minor part of the shape variation may be removed when excluding CVA 1, and this may impact the correlation analyses by lowering the probability of significant correlations between skull shape and, e.g., environmental variables.

The low $\theta$ values found among the spawning locations could indicate high gene flow, which is normally expected to lower the likelihood of local adaptation by natural selection, but the actual degree of adaptation is determined by an interaction between selective pressure and gene flow (e.g., Hendry et al. 2001). It is therefore possible for local populations to exhibit adaptation despite high gene flow (e.g., Saint-Laurent et al. 2003), and such a scenario could explain the significant variation in skull shape among locations. However, because of the migration patterns of the four spawning groups included here (Aro 1989), it can be questioned if there is much gene flow among them. This raises the possibility that the $\theta$ values are biased towards 0 because of large effective population sizes and lack of equilibrium between migration among spawning groups and random genetic drift within spawning groups, a process that is expected to take longer with increasing effective population sizes in each group and with a low number of migrants among groups (Chakraborty and Leimar 1987). Corresponding inaccuracies in morphological distances may arise when loci coding for morphological traits such as skull shape are not in selection-migration equilibrium. The present day connection between the Baltic Sea and the North Sea was formed through the Danish Straits 9500 10000 years ago (Ignatius et al. 1981). This is perhaps insufficient for the herring in the Baltic Sea to reach equilibrium.

To test directly whether differentiation in morphological traits is due to local adaptation by natural selection and not simply phenotypic plasticity, one may scan the entire genome of the organism under study as suggested by, e.g., Storz (2005) and Beaumont and Balding (2004) and compare genetic differentiation among populations at different loci (regions). To identify the ecological, environmental, or other factors that have major impacts on fish phenotypes, it may be necessary to conduct a common garden experiment or a reciprocal transplant experiment (e.g., Kawecki and Ebert 2004). Direct estimates of phenotypic plasticity in fish are so far uncommon, except for tests of the dependence of a few meristic traits on temperature during development, but a meta-analysis of 23 species of northern freshwater fish in postglacial lakes (Robinson and Parsons 2002) concluded that plasticity was a common response to varying environmental factors.

The significant morphometric differentiation among herring spawning groups excluding size variation was corre- 
lated to neutral molecular genetic differentiation but not to environmental distances in the present study. This suggests that shape is influenced by other, possibly biotic, factors not studied here. One such factor might be the species composition of mesozooplankton in the different areas of the Baltic, as this would lead to variation in feeding among spawning groups (Möllmann et al. 2004). In addition, we found that morphometric distances including size variation, as well as differences in mean vertebrae count, were correlated with environmental distances. These results suggest that herring in the Baltic Sea adapt to local environments in part by phenotypic plasticity, which has been argued to be the optimal strategy to coping in a heterogeneous environment, such as the Baltic Sea, on a short time scale (Robinson and Wilson 1994). It follows that although variation in herring morphology may indicate a potential for local adaptation to spawning and (or) nursery areas, morphological variation alone would be a dubious indicator of herring population structure on a regional scale.

\section{Acknowledgements}

We thank K-L. Mensberg, D. Meldrup, and T.B. Christensen for assisting in the DNA lab; A. Eskesen for assisting in digital photography and meristic counting; and J. Marcil and J. Lawlor (Dalhousie University, Halifax, Nova Scotia, Canada) for help with geometric morphometrics. Herring samples were kindly provided by J. Dröse (Federal Research Centre for Fisheries, Germany), G. Kornilovs (Latvian Fisheries Research Institute, Latvia), M. Rajasilta (Archipelago Research Institute, University of Turku, Finland), and L. Olofsson and G. Andersen (Sweden). H.B.H.J. received financial support from the Danish Network for Fisheries and Aquaculture Research (www.fishnet.dk) financed by the Danish Ministry for Food, Agriculture and Fisheries and the Danish Research Agency. The research project was also supported by a Marie Curie Transfer of Knowledge Fellowship BIORESC of the European Community's Sixth Framework Programme under contract No. MTKD-CT2005-029957. Furthermore, we thank the ConGen program (funded by the European Science Foundation) and the Danish Natural Science Research Council for support to C.P. and V.L. (grants No. 21-01-0526 and No. 21-03-0125).

\section{References}

Adams, D.C., and Funk, D.J. 1997. Morphometric inferences on sibling species and sexual dimorphism in Neoclamisus bebbinae leaf beetles: multivariate applications of the thin-plate spline. Syst. Biol. 46: 180-194.

Adams, D.C., and Rohlf, F.J. 2000. Ecological character displacement in Plethodon: biochemical differences found from a geometric morphometric study. Proc. Natl. Acad. Sci. U.S.A. 97: 4106-4111.

Adams, D.C., Rohlf, F.J., and Slice, D.E. 2004. Geometric morphometrics: ten years of progress following the 'revolution'. Ital. J. Zool. 71: 5-16.

Anonymous. 1962. Recommendations adopted by the Herring Committee. Rapp. P.-V. Cons. Perm. Int. Explor. Mer, 27 (Appendix 1): 72-96.

Aro, E. 1989. A review of fish migration patterns in the Baltic. Rapp. P.-V. Cons. Perm. Int. Explor. Mer, 190: 72-96.
Beaumont, M.A., and Balding, D.J. 2004. Identifying adaptive genetic divergence among populations from genome scans. Mol. Ecol. 13: 969-980.

Bekkevold, D., André, C., Dahlgreen, T.G., Clausen, L.A.W., Torstensen, E., Mosegaard, H., Calvalho, G.R., Christensen, T.B., Norlinder, E., and Ruzzante, D.E. 2005. Environmental correlates of population differentiation in Atlantic herring. Evolution, 59: 2656-2668.

Belkhir, K. 2000. GENETIX, logiciel sous Windows pour la génétique des populations. Laboratoire Génomes et Populations, Université de Montpellier, Montpellier, France.

Birdsall, K., Zimmerman, E., Teeter, K., and Gibson, G. 2000. Genetic variation for the positioning of wing veins in Drosophila melanogaster. Evol. Dev. 2: 16-24.

Bohonak, A.J. 2002. IBD (isolation by distance): a program for analyses of isolation by distance. J. Hered. 93: 153-154.

Bonin, A., Bellemain, E., Bronken Eidesen, P., Pompanon, F., Brochmann, C., and Taberlet, P. 2004. How to track and assess genotyping errors in population genetics studies. Mol. Ecol. 13: 3261-3273.

Bookstein, F.L. 1996. Biometrics, biomathematics and the morphometric synthesis. Bull. Math. Biol. 58: 313-365.

Caldecutt, W.J., and Adams, D.C. 1998. Morphometrics of trophic osteology on the three-spine stickleback, Gasterosteus aculeatus. Copeia, 1998: 827-838.

Chakraborty, R., and Leimar, O. 1987. Genetic variation within a subdivided population. In Population genetics and fisheries management. Edited by N. Ryman and F.M. Utter. University of Washington Press, Seattle, Washington. pp. 89-120.

Conover, D.O., Brown, J.J., and Ehtisham, A. 1997. Countergradient variation in growth of young striped bass (Morone saxatilis) from different latitudes. Can. J. Fish. Aquat. Sci. 54: 2401-2409.

Conover, D.O., Clarke, L.M., Munch, S.B., and Wagner, G.N. 2006. Spatial and temporal scales of adaptive divergence in marine fishes and the implication for conservation. J. Fish Biol. 69(Suppl. C): 21-47.

DeWoody, J.A., and Avise, J.C. 2000. Microsatellite variation in marine, freshwater and anadromous fishes compared with other animals. J. Fish Biol. 56: 461-473.

Estoup, A., Largiader, C.R., Perrot, E., and Chourrout, D. 1996. Rapid one-tube DNA extraction for reliable PCR detection of fish polymorphic markers and transgenes. Mol. Mar. Biol. Biotechnol. 5: 295-298.

Excoffier, L., Lval, G., and Schneider, S. 2005. Arlequin ver. 3.0: an integrated software package for population genetics data analysis. Evol. Bioinformatics Online, 1: 47-50.

Goudet, J. 1995. FSTAT. Version 1.2. A computer program to calculate $F$ statistics. J. Hered. 86: 485-486.

Goudet, J., Raymond, M., deMeeus, T., and Rousset, F. 1996. Testing differentiation in diploid populations. Genetics, 144: 1933-1940.

Guinand, B., Lemaire, C., and Bonhomme, F. 2004. How to detect polymorphisms undergoing selection in marine fishes? A review of methods and case studies, including flatfishes. J. Sea Res. 51: $167-182$.

Guo, S.W., and Thompson, E.A. 1992. Performing the exact test for Hardy-Weinberg proportion for multiple alleles. Biometrics, 48: 361-372.

Hammer, Ø., Harper, D.A.T., and Ryan, P.D. 2004. PAST PAlaeontological STatistics. Version1.21. folk.uio.no/ohammer/ past.

Hendry, A.P., Day, T., and Taylor, E.B. 2001. Population mixing and the adaptive divergence of quantitative traits in discrete populations: a theoretical framework for empirical tests. Evolution, 55: 459-466. 
International Council for the Exploration of the Sea. 2003. Report of the Herring Assessment Working Group for the area south of $62^{\circ} \mathrm{N}$. International Council for the Exploration of the Sea (ICES) CM 2003/ACFM:17.

Ignatius, H., Axberg, S., Niemistö, L., and Winterhalter, B. 1981. Quarternary geology of the Baltic Sea. In The Baltic Sea. Edited by A. Voipio. Elsevier Oceanography Series 30, Elsevier Scientific Publishing Company, Amsterdam, the Netherlands. pp. 54-69.

Insightful Corporation. 2002. S-PLUS. Version 6.1. Insightful Corporation, Seattle, Wash.

Jørgensen, H.B.H., Bekkevold, D., Hansen, M.M., Ruzzante, D.E., and Loeschcke, V. 2005. Marine landscapes and population structure of herring (Clupea harengus L.) in the Baltic Sea. Mol. Ecol. 14: 3219-3234.

Kawecki, T.J., and Ebert, D. 2004. Conceptual issues in local adaptation. Ecol. Lett. 7: 1225-1241.

Klingenberg, C.P., Barluenga, M., and Meyer, A. 2003. Body shape variation in cichlid fishes of the Amphilophus citrinellus species complex. Biol. J. Linn. Soc. 80: 397-408.

Klinkhardt, M. 1996. Der Hering Clupea harengus. Westarp Wissenschaften, Magdeburg, Germany.

Knutsen, H., Jorde, P.E., André, C., and Stenseth, C. 2003. Finescaled geographic population structuring in a highly mobile marine species: the Atlantic cod. Mol. Ecol. 12: 385-394.

Langerhans, R.B., and DeWitt, T.J. 2004. Shared and unique features of evolutionary diversification. Am. Nat. 164: 335-349.

Legendre, P., and Legendre, L. 1998. Numerical ecology. In Developments in environmental modelling, 20. Elsevier, Amsterdam, the Netherlands.

Manly, B.F.J. 1994. Multivariate statistical methods: a primer. 2nd ed. Chapman \& Hall, New York.

Marcil, J., Swain, D.P., and Hutchings, J.A. 2006. Genetic and environmental components of phenotypic variation in body shape among populations of Atlantic cod (Gadus morhua L.). Biol. J. Linn. Soc. 88: 351-265.

McPherson, A.A., Stephenson, R.L., O’Reilly, P.T., Jones, M.W., and Taggart, C.T. 2001a. Genetic diversity of coastal Northwest Atlantic herring populations: implications for management. J. Fish Biol. 59(Suppl. A): 356-370.

McPherson, A.A., O'Reilly, P.T., McParland, T.L., Jones, M.W., and Bentzen, P. 2001b. Isolation of nine novel tetranucleotide microsatellites in Atlantic herring (Clupea harengus). Mol. Ecol. Notes, 1: 40.

Möllmann, C., Kornilovs, G., and Sidrevics, L. 2000. Long-term dynamics of main mesozooplankton species in the central Baltic Sea. J. Plankton Res. 22: 2015-2038.

Möllmann, C., Kornilovs, G., Fetter, M., and Köster, F.W. 2004. Feeding ecology of central Baltic Sea herring and sprat. J. Fish Biol. 65: 1563-1581.

Neves, F.M., and Monteiro, L.R. 2003. Body shape and size divergence among populations of Poecilia vivipara in coastal lagoons of south-eastern Brazil. J. Fish Biol. 63: 928-941.

Nielsen, E.E., Hansen, M.M., Ruzzante, D.E., Meldrup, D., and Grønkjær, P. 2003. Evidence of a hybrid-zone in Atlantic cod (Gadus morhua) in the Baltic and the Danish Belt Sea revealed by individual admixture analysis. Mol. Ecol. 12: 1497-1508.

Nielsen, E.E., Nielsen, P.H., Meldrup, D., and Hansen, M.M. 2004. Genetic population structure of turbot (Scophthalmus maximus L.) supports the presence of multiple hybrid zones for marine fishes in the transition zone between the Baltic Sea and the North Sea. Mol. Ecol. 13: 585-595.

Ojaveer, E., and Elken, J. 1997. On regional subunits in the ecosystem of the Baltic Sea. In Proceedings of the 14th BMB Symposium, 5-
8 August 1995, Pärnu. Estonian Academy Publishers, Tallinn, Estonia. pp. 156-169.

Olsen, J.B., Lewis, C.J., Kretchmer, E.J., Wilson, S.L., and Seeb, J.E. 2002. Characterization of 14 tetranucleotide microsatellite loci derived from Pacific herring. Mol. Ecol. Notes, 2: 101-103.

Parmanne, R. 1990. Growth, morphological variation and migrations of herring (Clupea harengus L.) in the northern Baltic Sea. Fish. Res. 10: 1-48.

Parsons, L.S. 1972. Use of meristic characters and a discriminant function for classifying spring- and autumn-spawning Atlantic herring. Res. Bull. Int. Comm. Northw. Atl. Fish. 9: 5-9.

Pertoldi, C., García-Perea, R., Godoy, A., Delibes, M., and Loeschcke, V. 2005. Morphological consequences of range fragmentation and population decline on the endangered Iberian lynx (Lynx pardinus). J. Zool. 268: 73-86.

Popiel, J. 1984. On the biology of the Baltic herring. Rep. Sea Fish. Inst. 19: 7-16.

Raymond, M., and Rousset, F. 1995. GENEPOP. Version 1.2. A population genetics software for exact tests and ecumenicism. J. Hered. 86: 248-249.

Robinson, B.W., and Parsons, K.J. 2002. Changing times, spaces, and faces: tests and implications of adaptive morphological plasticity in the fishes of northern postglacial lakes. Can. J. Fish. Aquat. Sci. 59: 1819-1833.

Robinson, B.W., and Wilson, D.S. 1994. Character release and displacement in fishes: a neglected literature. Am. Nat. 144: 596-626.

Rohlf, F.J. 1999. Shape statistics: Procrustes superimpositions and tangent spaces. J. Classif. 16: 197-223.

Rohlf, F.J. 2003. tpsRegr - thin-plate spline regression software. Version1.28. Department of Ecology and Evolution, State University of New York at Stony Brook, New York.

Rüber, L., and Adams, D.C. 2001. Evolutionary convergence of body shape and trophic morphology in cichlids from Lake Tanganyika. J. Evol. Biol. 14: 325-332.

Ruzzante, D.E., Taggart, C.T., and Cook, D. 1998. A nuclear DNA basis for shelf- and bank-scale population structure in northwest Atlantic cod (Gadus morhua): Labrador to Georges Bank. Mol. Ecol. 7: 1663-1680.

Ruzzante, D.E., Mariani, S., Bekkevold, D., André, C., Mosegaard, H., Clausen, L.A.W., Dahlgren, T., Hutchinson, W.F., Hatfield, E.M.C., Torstensen, E., Brigham, J., Simmonds, E.J., Laikre, L., Larsson, L.C., Stet, R.J.M., Ryman, N., and Carvalho, G.R. 2006. Biocomplexity in a highly migratory pelagic marine fish, Atlantic herring. Proc. R. Soc. Lond. B Biol. Sci. 273: 1459-1464.

Ryman, N., Lagercrantz, U., Chakraborty, R., and Rosenberg, R. 1984. Lack of correspondence between genetic and morphological variability patterns in Atlantic herring (Clupea harengus). Heredity, 53: 687-704.

Saint-Laurent, R., Legault, M., and Bernatchez, L. 2003. Divergent selection maintains adaptive differentiation despite high gene flow between sympatric rainbow smelt ecotypes (Osmerus mordax Michill). Mol. Ecol. 12: 315-330.

SAS Istitute Inc. 1997. JMP. Version 3.2.2. SAS Institute Inc., Cary, N.C.

Schulte, P.M. 2001. Environmental adaptations as windows on molecular evolution. Comp. Biochem. Physiol. B, 128: 597-611.

Schultz, E.T., and Conover, D.O. 1997. Latitudinal differences in somatic energy storage: adaptive responses to seasonality in an estuarine fish (Atherinidae: Menidia menidia). Oecologia, 109: 516-529.

Sokal, R.R., and Rohlf, F.J. 1995. Biometry. W.H. Freeman and Company, New York. 
Storz, J.F. 2005. Using genome scans of DNA polymorphism to infer adaptive population divergence. Mol. Ecol. 14: 671-688.

Swain, D.P., and Foote, C.J. 1999. Stocks and chameleons: the use of phenotypic variation in stock identification. Fish. Res. 43: $113-128$.

Swain, D.P., Riddell, B.E., and Murray, C.B. 1991. Morphological differences between hatchery and wild populations of coho salmon (Oncorhynchus kisutch): environmental versus genetic origin. Can. J. Fish. Aquat. Sci. 48: 1783-1791.

Truett, G.E., Heeger, P., Mynatt, R.L., Truett, A.A., Walker, J.A., and Warman, M.L. 2000. Preparation of PCR-quality mouse genomic DNA with hot sodium hydroxide and Tris (HotSHOT). Biotechniques, 29: 52-54.

Valentin, A., Sévigny, J.-M., and Chanut, J.-P. 2002. Geometric morphometrics reveals body shape differences between sympatric redfish Sebastes mentella, Sebastes fasciatus and their hybrids in the Gulf of St Lawrence. J. Fish Biol. 60: 857-875. van Oosterhout, C., Hutchinson, W.F., Wills, D.P.M., and Shipley, P.F. 2003. Micro-Checker. Version 2.2.0. University of Hull, England.

Via, S., Gomulkiewicz, R., De Jong, G., Scheiner, S.M., Schlichting, C.D., and Van Tienderen, P.H. 1995. Adaptive phenotypic plasticity: consensus and controversy. Trends Ecol. Evol. 10: 212-217.

Weir, B.S., and Cockerham, C.C. 1984. Estimating $F$-statistics for the analysis of population structure. Evolution, 38: 1358-1370.

Workman, M.S., Leamy, L.J., Routman, E.J., and Cheverud, J.M. 2002. Analysis of QTL effects on the size and shape of mandibular molars in mice. Genetics, 160: 1573-1586.

Zar, J.H. 1996. Biostatistical analysis. Prentice-Hall International, Inc., Upper Saddle River, N.J.

\section{Appendix A}

Table A1. Data summary for microsatellite markers.

\begin{tabular}{|c|c|c|c|c|c|c|c|c|c|}
\hline & СНА1017 & СНА1020 & CHA1202 & CHA1027 & CPA101 & CPA107 & CPA111 & CPA112 & CPA114 \\
\hline \multicolumn{10}{|l|}{$\mathbf{B B O 2}^{a}$} \\
\hline No. alleles & 10 & 20 & 12 & 21 & 21 & 4 & 5 & 13 & 20 \\
\hline$H_{\mathrm{EXP}}$ & 0.804 & 0.909 & 0.789 & 0.936 & 0.915 & 0.571 & 0.376 & 0.764 & 0.916 \\
\hline$P($ HWeq $)$ & 0.885 & 0.560 & 0.382 & 0.551 & 0.530 & 0.049 & 0.747 & 0.200 & 0.831 \\
\hline \multicolumn{10}{|l|}{ BB03 } \\
\hline$H_{\mathrm{OBS}}$ & 0.779 & 0.929 & 0.771 & 0.860 & 0.938 & 0.576 & 0.421 & 0.821 & 0.911 \\
\hline$P($ HWeq $)$ & 0.739 & 0.222 & 0.980 & 0.101 & 0.963 & 0.099 & 0.641 & 0.102 & 0.686 \\
\hline \multicolumn{10}{|l|}{ AL02 } \\
\hline No. alleles & 10 & 19 & 10 & 20 & 19 & 4 & 7 & 14 & 16 \\
\hline$H_{\mathrm{EXP}}$ & 0.778 & 0.911 & 0.732 & 0.923 & 0.914 & 0.625 & 0.422 & 0.753 & 0.913 \\
\hline \multicolumn{10}{|l|}{ AL03 } \\
\hline$H_{\mathrm{EXP}}$ & 0.807 & 0.916 & 0.810 & 0.928 & 0.906 & 0.547 & 0.391 & 0.755 & 0.919 \\
\hline$H_{\mathrm{OBS}}$ & 0.771 & 0.889 & 0.780 & 0.908 & 0.861 & 0.537 & 0.385 & 0.697 & 0.887 \\
\hline$P($ HWeq $)$ & 0.749 & 0.070 & 0.059 & 0.208 & 0.297 & 0.854 & 0.337 & 0.402 & 0.053 \\
\hline \multicolumn{10}{|l|}{ RI03 } \\
\hline No. alleles & 11 & 18 & 12 & 19 & 22 & 5 & 5 & 13 & 17 \\
\hline$H_{\mathrm{EXP}}$ & 0.799 & 0.914 & 0.776 & 0.914 & 0.917 & 0.566 & 0.390 & 0.717 & 0.914 \\
\hline$H_{\mathrm{OBS}}$ & 0.752 & 0.898 & 0.761 & 0.907 & 0.926 & 0.459 & 0.358 & 0.741 & 0.906 \\
\hline$P($ HWeq $)$ & 0.244 & 0.474 & 0.183 & 0.898 & 0.372 & 0.001 & 0.505 & 0.107 & 0.267 \\
\hline \multicolumn{10}{|l|}{ RU0303 } \\
\hline No. alleles & 8 & 17 & 11 & 18 & 19 & 4 & 6 & 16 & 16 \\
\hline$P($ HWeq $)$ & 0.801 & 0.131 & 0.807 & 0.403 & 0.645 & 0.000 & 0.056 & 0.927 & 0.032 \\
\hline
\end{tabular}

Note: $H_{\text {EXP. }}$ expected heterozygosity; $H_{\mathrm{OBS}}$, observed heterozygosity; $P$ values in bold type indicate departure from Hardy-Weinberg equilibrium (HWeq), as revealed using the test by Guo and Thompson (1992) and Dunn-Šidák adjusting the $\alpha$ to $0.0073(k=9$, the number of loci used for each sample).

${ }^{a}$ See Table 1 for explanation of sample codes. 